\title{
BIBLIOTECA, CURRÍCULO E MÚSICA NA ESCOLA: UM RELATO DE EXPERIÊNCIA
}

\author{
Miriã Santana Veiga \\ Mestre em Educação \\ Bacharel em Biblioteconomia / Ciências da Informação \\ miria.veiga@ifro.edu.br \\ Jussara Santos Pimenta \\ Doutora em Educação \\ Docente da Universidade Federal de Rondônia (UNIR) \\ jussara.pimenta@unir.br \\ Ezenice Costa de Freitas Bezerra \\ Mestre em Educação Profissional \\ Docente do Curso de Música da Universidade Federal de Rondônia (UNIR) \\ ezenice.bezerra@unir.br
}

\section{Resumo}

\begin{abstract}
Este artigo tem por objetivo apresentar uma breve discussão sobre os conceitos de currículo, currículo oculto, cultura e em seguida apresenta dois relatos de experiências culturais, em dois espaços escolares: a sala de aula e a biblioteca escolar. Na sala de aula o uso da música e na biblioteca escolar, o incentivo à leitura. Para tanto buscamos fundamentar nossos conteúdos em pesquisadores que defendem a valorização da cultura nos currículos. Nos relatos de experiências percebemos como é gratificante o incentivo à cultura nas escolas e de que como foi possível melhorar o ambiente escolar.
\end{abstract}

Palavras-chave: Currículo; Cultura; Biblioteca; Música.

\section{INTRODUÇÃO}

Este artigo trata sobre os conceitos de currículo, currículo oculto, cultura e um breve relato de experiências culturais, na música e na biblioteca escolar, mostrando que é possível inserir projetos de incentivo à leitura e a educação musical, que hoje faz parte do currículo escolar para a educação básica. Cabe ressaltar que as experiências em educação musical terão como base a observação de alunos estagiários do curso de Licenciatura em Música da Universidade Federal de Rondônia (UNIR).

A experiência em Biblioteca escolar focou-se em duas campanhas de arrecadação de livros de literatura, desenvolvidos pela equipe da biblioteca do Instituto Federal de Educação, Ciência e Tecnologia de Rondônia (IFRO) Campus Porto Velho Calama, com o objetivo de atrair os alunos à biblioteca e incentivar o hábito da leitura.

Muitas discussões têm surgido sobre currículo e cultura, principalmente de como inserir estes conhecimentos na escola, buscando criar um senso crítico do mundo em que o aluno está inserido. Mas como é possível fazer uma educação de qualidade para todos, num país com tanta diversidade cultural?

Para isso, fundamentamos nosso trabalho em Candau e Moreira (2007), que trata sobre currículo, conhecimento e cultura. Os dois autores defendem a diversificação do currículo imposto pelo estado, defendendo que a cultura deve ser um dos principais eixos das práticas pedagógicas. Sobre música e educação utilizamos Sobreira (2014) que apresenta conexões entre Educação Musical e o campo do currículo e sobre a biblioteca escolar e o incentivo ao seu uso e 
valorização utilizamos Milanesi (2002) e Campello (2009).

\subsection{OBJETIVO GERAL:}

Mostrar através de relatos de experiência desenvolvidos em dois ambientes escolares na cidade de Porto Velho Capital do Estado de Rondônia, que é possível Trabalhar a cultura na escola seja através da formação de professores de música ou através do trabalho de bibliotecários e auxiliares de biblioteca.

\subsection{OBJETIVOS ESPECÍFICOS:}

- Incentivar a cultura nas escolas através de atividades desenvolvidas com a música (relato de experiência numa escola de educação infantil).

- Promover incentivo à leitura através de ações educativas na biblioteca (relato de experiência no Instituto Federal de Porto Velho, RO).

\section{CURRÍCULO E CURRÍCULO OCULTO}

É por intermédio do currículo que se sistematizam os esforços pedagógicos, a fim de torna- lo mais atraente, onde todos atuam para sua elaboração mesmo em diferentes níveis do processo educacional. Daí a necessidade de discussões e reflexões sobre o currículo, pois, são os eixos norteadores que orientam o ensino ofertado pelas escolas, e que são influenciados por fatores socioeconômicos, históricos, políticos e culturais. Candau e Moreira (2007) apresentam cinco tópicos que discorrem sobre o que é currículo:

(a) os conteúdos a serem ensinados e aprendidos; (b) as experiências de aprendizagem escolares a serem vividas pelos alunos; (c) os planos pedagógicos elaborados por professores, escolas e sistemas educacionais; (d) os objetivos a serem alcançados por meio do processo de ensino; (e) os processos de avaliação que terminam por influir nos conteúdos e nos procedimentos se nos diferentes graus da escolarização (CANDAU; MOREIRA, 2007, p.18).

De acordo com Candau e Moreira (2007):

Estamos entendendo currículo como as experiências escolares que se desdobram em torno do conhecimento, em meio a relações sociais, e que contribuem para a construção das identidades de nossos/as estudantes. Currículo associa-se, assim, ao conjunto de esforços pedagógicos desenvolvidos com intenções educativas, por esse motivo, a palavra tem sido usada para todo e qualquer espaço organizado para afetar e educar pessoas, o que explica o uso de expressões como o currículo da mídia, o currículo da prisão etc. Nós, contudo, estamos empregando a palavra currículo apenas para nos referirmos às atividades organizadas por instituições escolares. Ou seja, para nos referirmos à escola. (CANDAU; MOREIRA, 2007, p.18)

Existe também, dentro do contexto escolar, atitudes e valores transmitidos subliminarmente pelas relações sociais e pelas rotinas do cotidiano, como por exemplo: a arrumação das carteiras nas salas de aula, a forma de chamar a professora e as visões de família que ainda se encontram em certos livros didáticos, isso tudo se denominam "currículo oculto". Estas práticas também fazem parte sistemática da escola e a biblioteca se insere participando diretamente dos processos educacionais, do letramento informacional dos alunos e do conhecimento que deverá ser levado para toda a vida acadêmica do discente. Assim como também as práticas da educação musical com apresentações dos alunos em dias festivos, festivais de música, projetos musicais que incentivam os alunos a praticarem o currículo oculto, que vai além do que normalmente os alunos estão acostumados a ver no dia a dia da escola (SOBREIRA, 2014, p.08).

\section{CULTURA}

Cultura é o complexo dos padrões de comportamento, das crenças, das instituições, das manifestações artísticas, intelectuais, etc. Que são transmitidos coletivamente e típicos de uma sociedade. (AURÉLIO, 2016, p.288).

O termo cultura vem atravessando o tempo com vários significados. Primeiro como cultivo da terra século XV, segundo como um termo de cultivo da mente humana que ganhou um caráter classista no século XVIII, pois, só as classes ricas da sociedade europeia poderiam ter cultura, isto é o refinamento intelectual e artístico, que os caracterizavam como cultos. No século XX o termo cultura 
passa a abranger e incluir a cultura popular, a cultura das massas.

Fica evidentemente que a valorização do termo cultura, passa o sentido de bem cultural elevado da classe rica, em detrimento da cultura popular nas escolas. CANDAU e MOREIRA (2007) defendem que:

A forma geral de vida de um dado grupo social, com as representações da realidade e as visões de mundo adotadas por esse grupo. A expressão dessa concepção, no currículo, poderá evidenciar se no respeito e no acolhimento das manifestações culturais dos(as) estudantes, por mais desprestigiadas que sejam. (CANDAU; MOREIRA, 2007, p.27).

Portanto, se torna evidente que vivemos em um mundo de pluralidades culturais, da diversidade e isso deve ser vivenciado e respeitado dentro das instituições de ensino, desde os aos iniciais até a graduação, Candau e Moreira apud Stuart Hall: Por bem ou por mal, a cultura é agora um dos elementos mais dinâmicos - e mais imprevisíveis - da mudança histórica no novo milênio. Não deve nos surpreender, então, que as lutas pelo poder sejam, crescentemente, simbólicas e discursivas, ao invés de tomar, simplesmente, uma forma física e compulsiva, e que as próprias políticas assumam progressivamente a feição de uma política cultural. (CANDAU; MOREIRA, 2007, p. 20).

A pluralidade cultural possibilita então a renovação das práticas pedagógicas, pois a escola deve socializar todo o tipo de conhecimento e facilitar o acesso dos estudantes a outros saberes e diversidades.

Dentro da escola o professor de música e o bibliotecário atuam como educadores e são também agentes culturais, que tem o dever de promover a valorização e o respeito por intermédio do currículo escolar e da cultura, onde Candau e Moreira (2007, p.28) "[...] afirma que é um campo em que se tenta impor tanto a definição particular de cultura de um dado grupo quanto o conteúdo dessa cultura[...]".

\section{UM RELATO DE EXPERIÊNCIA - A MÚSICA NA ESCOLA}

Em decorrência a discussão sobre a diversidade cultural que existe na escola, trazemos este relato de experiência de um período de observação como professora orientadora dos meus alunos de estágio supervisionado do curso de Licenciatura em Música da Universidade Federal de Rondônia (Unir), numa escola que está localizada no centro de Porto Velho, que funciona há cinco anos e trabalha com crianças em idade préescolar da educação infantil.

\subsection{PERFIL DOS ALUNOS}

Os alunos estavam no oitavo período do curso de Licenciatura em Música da Unir, ano de conclusão. Durante o período de estágio passaram por outras escolas em etapas diferentes, mas apenas como observadores das aulas. Este relato ocorreu de agosto a dezembro de 2013.

É importante ressaltar que a escola citada não possui professores na área musical, sendo o professor polivalente ensinando todas as disciplinas para os alunos.

\subsubsection{Relato de experiência: Um som diferente na escola!}

Quando iniciamos com os alunos o processo de entrada na escola, havia certa expectativa no ar. Era a primeira vez que os alunos estagiários entrariam numa sala de aula com alunos pequenos, e para alguns seria um grande desafio.

A direção da escola, por outro lado, estava empolgada em saber que teriam alunos da universidade trabalhando música com as crianças, o que na verdade é raro de acontecer em qualquer escola neste período, pois os professores, em sua maioria, utilizam a música como um currículo oculto, e apenas a utilizam como um "enfeite" durante as aulas, ou nas programações da escola. Então havia uma grande expectativa de ambas as partes. Começamos distribuindo os alunos de acordo com suas preferências de idade nas salas, $e$ assim iniciamos as aulas, onde cada aluno era responsável, durante uma manhã na semana, de conduzir a aula. Cada um trazia seu plano de aula e entregava a professora que, observava em alguns momentos e participava com os alunos em outros.

Eram jogos musicais, músicas e cantigas de roda, exercícios de percepção musical, histórias, demonstração dos instrumentos musicais, iniciação ao coralito (coral de crianças) e brincadeiras voltadas para o tema sugerido para a aula de educação musical.

Interessante que os alunos a cada semana estavam mais envolvidos com as aulas e já 
perguntavam sempre quando e a que horas os alunos estagiários chegariam na escola, e além disso as crianças criaram laços emocionais muito fortes com eles, o que levava $v$ os alunos estagiários a verem como um trabalho de educação musical na escola pode transformá-la.

Um som diferente surgia a cada encontro. Era maravilhoso ver! Durante três meses vi o desenvolvimento pedagógico de cada aluno estagiário e o deslumbramento deles em ver como a música tem um papel importante para o crescimento social, físico e emocional da criança, que mesmo em idade tão tenra já absorve com tamanha desenvoltura a música.

Ao final do periodo os alunos promoveram um recital de todas as turmas envolvidas no estágio o que mexeu com toda a escola, onde professores, alunos, estagiários e a comunidade estavam juntos. Ver as crianças cantando e tocando mexeu com a emoção de todos os participantes. Muitos alunos estagiários descobriram um potencial que nem eles mesmos sabiam que possuíam quanto ao ato de ensinar, quanto ao cumprir de um currículo e ao processo de construção de experiências musicais. Sei que foi um marco na vida de todos.

A análise que fazemos após este período é que, mesmo diante de tantos obstáculos encontrados na escola, quanto ao espaço físico que a escola não tem para realizar uma aula de educação musical, mesmo sem um professor específico para a área musical, mesmo sem interesse do Estado em promover políticas públicas para que sejam oferecidas vagas para professores de música para a educação infantil, ainda assim vale a pena investir. Vale a pena ver que, através de momentos como estes, que a cultura e o currículo podem ser trabalhados (mesmo sendo o currículo oculto), ensinados, apreciados pelas crianças que ainda estão em processo de formação.

Cabe, entretanto analisar vários pontos que agregam este relato a fim de que haja uma reflexão quanto ao currículo e a cultura em sala de aula, que ainda precisam de melhorias quanto ao incentivo no Estado de Porto Velho. Primeiro, o conhecimento cultural de cada professor que ainda é deficiente no preparo para aulas de música.

Segundo, a polivalência que sugerem ao professor da educação infantil que agrega um fardo pesado, pois, precisa de tempo para o preparo das várias disciplinas que lhe são atribuídas. E terceiro, o excesso de horas trabalhadas, muita das vezes em dois períodos, para uma melhoria financeira o que acarreta cansaço extremo, pois cuidar de crianças pequenas é muito mais pesado que com alunos mais velhos. Porém, nossa esperança é que através de posturas positivas da educação surjam novas estratégias educacionais onde professores e alunos alcancem uma educação de qualidade para o futuro.

\section{UM RELATO DE EXPERIENCIA - A BIBLIOTECA ESCOLAR E O INCENTIVO A LEITURA}

As bibliotecas são centros culturais, "são espaços de preservação do patrimônio intelectual, literário, artístico e científico das sociedades [...]" (HUBNER, 2014, p.09), guardam a memória escrita de um povo ou de uma nação, "desde seus primórdios o homem vem procurando formas de guarda e proteger o conhecimento [...]" (MILANESI, 2002, p. 33). $\mathrm{O}$ conhecimento humano desenvolvesse sobre o respaldado das descobertas anteriores, pois não há um conhecimento novo, sem que se conheçam os que o antecederam. Portanto, as bibliotecas por si só são espaços genuínos de incentivo ao saber, seja ele impresso, virtual ou imagético. Mas como incentivar o saber? Se vivemos em uma sociedade com graves índices de analfabetismo, ou pior, têm os que sabem ler, mas não conseguem interpretar textos mínimos, são os analfabetos funcionais.

Nos dias atuais a demanda do mercado de trabalho que busca, por profissionais que saibam não apenas ler, mas interpretar, escrever, assimilar diversos tipos de informações e dominar as tecnologias da informação.

Nos últimos anos a educação brasileira se expandiu, desde a educação infantil até o ensino superior, mas o que ganhou destaque nesse período foi a criação e o fortalecimento dos institutos federais (IF), que têm por objetivo formar profissionais técnicos qualificados para o mercado de trabalho.

No estado de Rondônia existem oito Institutos Federais de Educação Ciência e Tecnologia (IFRO). Oliveira e Amaral (2012, p. 2) afirmam que: "[...] nesse sentido, as bibliotecas dos campi dos IF atuam como agentes fundamentais na concretização da missão dos IF, fomentando ensino, pesquisa e 
extensão, necessitando adequar-se a essa realidade $[\ldots]$ "..

Este relato é sobre uma experiência vivida na Biblioteca do campus IFRO Porto Velho Calama, localizada atualmente na Avenida Calama, na cidade de Porto velho. A experiência tinha por objetivo melhorar o acervo da biblioteca e atrair os alunos e incentivar o hábito da leitura.

CAMPELLO (2009) afirma que:

No caso do bibliotecário, a preocupação com a dinamização da leitura deve ser creditada às circunstâncias que dificultam a existência de uma relação positiva da criança e do jovem com a biblioteca. É sabido que a maioria das bibliotecas escolares, além de conviverem com uma realidade de faltas e carências, apresentam imagem de espaço sisudo, de silêncio, pouco atraente [....]. A dinamização para atrair usuários envolve duas ações específicas: transformar a biblioteca em um espaço dinâmico por meio de atividades variadas de leitura e/ou num espaço atraente, por meio de uma organização física alegre e convidativa (CAMPELLO, 2009, 68 p.)

\subsection{RELATO DE EXPERIÊNCIA: NÃO PRECISAMOS DE LIVROS DE LITERATURA, SOMOS UMA ESCOLA TÉCNICA!}

Ao ingressarmos no IFRO em outubro de 2013, imaginamos trabalhar em uma biblioteca moderna e cheia de livros que contribuísse com a formação de excelentes profissionais. Mas a realidade não era diferente da já vivida e trágica rotina da grade maioria das bibliotecas escolares brasileiras. Consideradas o lugar do docente readaptado, o lugar da punição, o depósito de livro didático e outros.

Optamos, primeiramente, por observar a rotina da biblioteca, dos servidores e alunos. Percebemos que a biblioteca era o lugar do ócio, da diversão, pois ali se namorava, fugia das aulas, jogava-se e principalmente, era um bom lugar para namoricos.

\subsubsection{Acervo da Biblioteca:}

A biblioteca tinha 3.727 livros novos $e$ alguns usados, mas o que nos surpreendeu, foi a enorme quantidade de livros didáticos usados e vencidos, na contagem da época somou-se mais de oito mil livros. Tudo isso aglomerado em um espaço minúsculo de quase
80 metros quadrados, sem mencionar os móveis e estantes que estavam no local.

Verificando o acervo, ficou evidente a falta de livros de literatura, tanto de títulos nacionais, quanto de títulos estrangeiros, havia menos de quinze obra, para atender um público de mil pessoas entre, professores técnicos e alunos.

Outra questão era o comportamento dos alunos, não existia ali uma cultura de biblioteca, tanto por parte dos alunos, quanto por parte da própria administração. Por isso a frase em destaque na abertura deste relato. Pois no instituto havia na época quase mil alunos, em sua maioria adolescentes, que nas observações realizadas adoravam ler livros de ficção cientifica, romances e outros. Queríamos que os alunos valorizassem a biblioteca, não apenas para estudar os livros exigidos pelos docentes, mas que cultivassem uma cultura de biblioteca. A primeira ação tomada foi sentar coma administração e falar sobre a importância da biblioteca escolar e do apoio que deveria ser dado ao equipe da Unidade de Informação. Nesse sentido queríamos incentivar os alunos a ler, educar os alunos, comprar livros de literatura $e$ melhorar os relacionamentos interpessoais da equipe da biblioteca, com a sua comunidade, neste caso a maioria era composta de adolescentes.

Por isso organizamos uma caixa de sugestões de títulos de livros para que fossem comprados para o acervo. Depois de uma semana de sugestões coletadas, quase $100 \%$ das sugestões era de livros de literatura, como por exemplo: Coleção Harry Potter, O mundo de Sofia, o pequeno príncipe e outro. Os alunos ficaram animados, e fomos atrás da compra, mas fomos informados que os livros de literatura, não eram prioridade do Campus e que deveriam esperar. Mas isso não nos desanimou, nosso objetivo era de nos aproximar de nossa comunidade discente e incentivar o hábito da leitura, então tivemos a ideia de organizar uma campanha de arrecadação de livros de literatura.

Estávamos entrando no mês de junho, o mês dos namorados, com o tema "Tá a fim de um romance! Doe um livro", começamos nossos trabalhos, o primeiro passo foi espalhar poesias por toda a biblioteca.

Decoramos com corações e incentivamos a comunidade a participar da campanha, foram 
enviados e-mail marketing e publicações nas redes sociais.

$O$ resultado foi um sucesso quase todas as obras da lista foram arrecadadas e no fim inserimos nos acervo mais de 240 livros de literatura. $O$ acervo passou a ser procurado pelos alunos, atrás dos livros recebidos, ganhamos o respeito $e$ o apoio total da administração do Campus que percebeu a importância da literatura na escola e, além disso, nossos alunos agora tinham opção para ler, o que nos deixou gratificados. De uma mera prateleira de livros agora tínhamos uma opção de mais de 250 títulos.

Como análise final dessa atividade cultural, verificamos que mesmo dentro da rede tecnológica ensino, há uma ideia diferente do que venha ser Biblioteca Escolar e da sua importância, no incentivo a leitura. Cabe ao bibliotecário escolar, lutar para mudar essa situação, por isso das grandes campanhas com o objetivo e sensibilizar a administração, de tirar o estigma de caixa de livro das Bibliotecas Escolares e de seu potencial centro disseminador de cultura, realizando assim a inclusão informacional desses jovens.

\section{CONSIDERAÇÕES FINAIS}

Diante dos temas apresentados neste artigo, vemos a necessidade de incentivarmos a cultura na escola, como um dos desafios ao sistema excludente e alienador que temos nos dias atuais. Torna-se necessário reafirmarmos que a diversidade cultural é a grande motivadora desta construção cultural, onde não são apenas as disciplinas ditas "prioritárias" que levam os alunos a mudarem suas atitudes e pensamentos quanto à vida e ao futuro.

Em um país como o Brasil, formado historicamente por diversas culturas trazidas de todo o mundo, uma delas por seres humanos escravizados, como a cultura afro. Surge a seguinte pergunta: será que não há espaço dentro dos currículos escolares para olhar para o outro com o mínimo de respeito? Ou se também como educadores vivenciaremos, ainda mais, a barbárie da ignorância?

A falta de respeito a cultura do outro, se torna evidente, nos grandes embates e conflitos genocidas atuais, a era da barbárie alimentada, pelo não aceitar a religião e o modo de vida do outro.

Até onde iremos como sociedade, se não valorizamos as nossas peculiaridades culturais? Seremos tão cruéis ao ponto de como educadores apoiar um currículo excludente e sistemático, voltado exclusivamente para o mercado de trabalho? Ao apresentarmos dois breves relatos sobre atividades de incentivo a cultura pela música e pela leitura mostramos que é possível mudar esse cenário.

\title{
LIBRARY, CURRICULUM AND MUSIC AT SCHOOL: A REPORT OF EXPERIENCE
}

\begin{abstract}
This article aims to present a brief discussion about the concepts of curriculum, hidden curriculum, and culture and then presents two reports of cultural experiences in two school spaces: the classroom and the school library. In the classroom the use of music and in the school library, encourage reading. Therefore, we seek to base our contents on researchers who defend the appreciation of culture in curricula. In our experience reports, we see how rewarding is the incentive to culture in schools, and how it has been possible to improve the school environment
\end{abstract}

Keywords: Curriculum; Culture; Library; Music 


\section{REFERÊNCIAS}

ASSOCIAÇÃO BRASILEIRA DE NORMAS TÉCNICAS. NBR 6023: informação e documentação referências - elaboração. Rio de Janeiro, 2002.

ASSOCIAÇÃO BRASILEIRA DE NORMAS TÉCNICAS. NBR 10520: informação e documentação - citações em documentos apresentação. Rio de Janeiro, 2002.

CANDAU; Vera Maria; MOREIRA. Antônio Flávio Barbosa. Indagações sobre currículo: currículo, conhecimento e cultura. Brasília: Ministério da Educação, 2007.

MILANESI, Luís. Biblioteca. São Paulo: Ateliê Editora, 2002.

CAMPELLO, Bernadete Santos. Letramento informacional no Brasil: práticas educativas de bibliotecários em escolas de ensino básico. Minas Gerais. Tese (Doutorado em Ciência da Informação) -. Universidade Federal de Minas Gerais, 2009.

HÜBNER, Marcos Leandro Freitas. A Biblioteca universitária na formação acadêmica: história da biblioteca central da Universidade de Caxias do Sul e sua relação com a aprendizagem e o sucesso acadêmico. Dissertação (Mestrado em Educação) Universidade de Caxias do Sul, 2014. Disponível em: < https://repositorio.ucs.br/jspui/bitstream/1133 8/674/1/Dissertacao\%20Marcos\%20Leandro $\% 20$ Freitas\%20Hubner.pdf $>$. Acesso em: 16 jul. 2015.

INSTITUTO FEDERAL DE RONDÔNIA. Regimento Geral do IFRO. Porto Velho, 2011. Disponível em: <http://www.ifro.edu.br/site/wpcontent/uploa ds/2009/04/RegimentoGeral. pdf $>$. Acesso em: 24 jul. 2015.

OLIVEIRA, Greissi Gomes; AMARAL, Roniberto Morato do. Mapeamento de processos em bibliotecas: um estudo de caso em uma biblioteca do Instituo Federal de Educação, Ciência e Tecnologia de São Paulo. In: SEMINÁRIO NACIONAL DE BIBLIOTECAS UNIVERSITÁRIAS, 17., Gramado, 2012. Anais... Porto Alegre: UFRS,
2012.

Disponível

em: http://periodicos.sbu.unicamp.br/ojs/index.ph p/rdbci e em Rev. Digit. Bibliotecon. Cienc. Inf. Campinas, SP v.13 n.3 p.526-545 set./dez. $2015 . \quad$ Disponível em: <http://200.136.214.89/nit/refbase/arquivos/ol iveira/2012/603_Oliveira+Amaral2012.pdf>. Acesso em: 06 jan. 2016.

SOBREIRA, Silvia Garcia. Conexões entre educação musical e o campo do currículo. Revista ABEM, Londrina, v. 22, n. 33, 2014. 